\title{
ANNOUNCEMENT
}

ROYAL COLLEGE OF PHYSICIANS OF EDINBURGH

Second International Symposium

on

\section{FIBRINOGEN AND CARDIOVASCUIAR} DISEASE

Tuesday 1 and Wednesday 2 November 1994

SECOND ANNOUNCEMENT

Sessions (reviews and free communications) will include:

- Biochemistry and measurement of fibrinogen

- Fibrinogen and the arterial wall

- Genetic control of plasma fibrinogen levels

- Epidemiology of plasma fibrinogen

- Fibrinogen and ischaemic heart disease

- Fibrinogen and peripheral arterial disease

- Fibrinogen and cerebrovascular disease

- Therapeutic reduction of plasma fibrinogen

Education, Audit and Research Department, Royal College of Physicians of Edinburgh

9 Queen Street

Edinburgh EH2 1JQ

Scotland - UK 